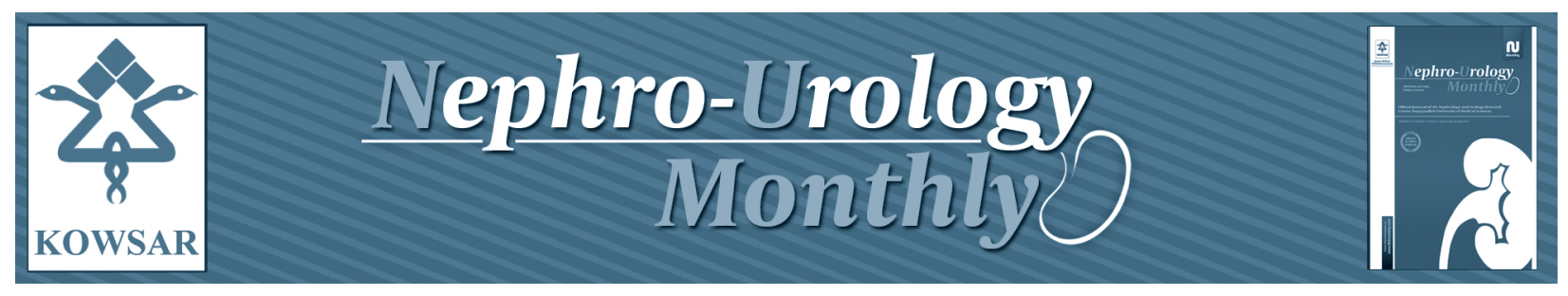

\title{
Urinary Neutrophil Gelatinase Associated Lipocalin (NGAL) for Early Diag- nosis of Acute Kidney Injury in Renal Transplant Recipients
}

\author{
Zohreh Rostami ${ }^{1, *}$, Mohammad Nikpoor ${ }^{1}$, Behzad Einollahi $^{1}$ \\ ${ }^{1}$ Nephrology and Urology Research Center, Baqiyatallah University of Medical Sciences, Tehran, IR Iran \\ * Corresponding author: Zohreh Rostami, Nephrology and Urology Research Center, Baqiyatallah University of Medical Sciences, Tehran, IR Iran. Tel: +98- \\ 9121544897, Fax: +98-2181262073, E-mail: rostami@numonthly.com.
}

\begin{abstract}
A B S T R A C T
Background: Early predictive biomarkers for acute kidney injury(AKI) such as neutrophil elatinase-associated lipocalin(NGAL) could identify patients who may benefit from early initiation of treatment.

Objectives: We aimed to obtain a cut off point for AKI prediction by urine NGAL in kidney transplantation.

Patients and Methods: In a prospective cohort study, 64 adult who underwent kidney transplantation from living or deceased donors at Baqiyatallah transplant center between April 2009 and January 2010 were included. Patients divided into two groups based on the presence or absence of graft dysfunction. In this study, early graft dysfunction (post transplantation AKI) was defined as Cr level more than $1.5 \mathrm{mg} / \mathrm{dL}$ on the second postoperative day.

Results: Post-transplant AKI was observed in 31 recipients. Mean urinary NGAL level was greater in recipients with AKI $(\mathrm{P}=0.024)$. In linear regression model, AKI was only factor affected on urinary NGAL level $(B=299.8, P=0.009)$. The best sensitivity and specificity for AKI detection by urinary NGAL observed at 2 hour after operation with cut-off point $204 \mathrm{ng} / \mathrm{mL}$.

Conclusions: Our study showed in those who developed early post transplantation graft dysfunction the best AUC-ROC for urine NGAL observed at a cut-off value of $204 \mathrm{ng} / \mathrm{mL}$ after 2 hour post transplantation.
\end{abstract}

Keywords: Neutrophil Gelatinase-associated Lipocalin Protein, Rat; Acute Kidney Injury; Kidney Transplantation

Copyright $\odot$ 2013, Nephrology and Urology Research Center; Published by Kowsar Corp.

\section{Background}

Acute kidney injury (AKI) occurs to some extent almost always in deceased kidney transplants due to renal ischemia-reperfusion, and even in some live donor allografts, and commonly causes varying degrees of early renal allograft impairment $(1,2)$ that predisposes patients to acute and chronic rejection (2). Therefore, early predic- tive allograft dysfunction biomarkers could identify patients who may benefit from early initiation of treatment(3). According to the RIFLE criteria, AKI was defined as an abrupt increase in serum $\mathrm{Cr}$ of at least to more than $150 \%$ (1.5-fold from baseline) and traditionally identified by measurement of serum creatinine (Cr) (4). Unfortunately, $\mathrm{Cr}$ is an unreliable indicator for AKI, and it cannot

-Article type: Research Article; Received: 01 Dec 2012, Revised: 12 Dec 2012, Accepted: 29 Dec 2012; DOI: 10.5812/numonthly.9385

Implication for health policy/practice/research/medical education:

This is an article about early diagnosis of acute kidney injury in kidney transplant recipients with a new kidney injury biomarker (NGAL).

>Please cite this paper as:

Rostami Z, Nikpoor M, Einollahi B. Urinary Neutrophil Gelatinase Associated Lipocalin (NGAL) for Early Diagnosis of Acute Kidney Injury in Renal Transplant Recipients. Nephro-Urol Mon.2013;5(2):745-52. DOI:10.5812/numonthly.9385 
timely and accurately reflect situation of renal function unless a steady state has been obtained, which may require several days (1). Thus, considerable rises in serum $\mathrm{Cr}$ does not appear until 48-72 h after initial insult (5). However, several studies $(4,6,7)$ have revealed that neutrophil gelatinase-associated lipocalin (NGAL) has significantly increased in urine and plasma among patients with AKI, NGAL increment occurs $24-48 \mathrm{~h}$ before the rise in serum $\mathrm{Cr}(5,8)$. NGAL is emerging as a convenient biomarker for predicting AKI even in patients with multiple comorbid disease and with unknown point in time from the beginning of kidney injury (9).

In addition, one of the necessities for clinical use of any AKI biomarkers is a cut-off determination for defining abnormality (7). Recently, few studies $(6,10-12)$ reported different sensitivity, specificity and AUCs for the diagnosis of AKI, which are essential to determine the accuracy of the biomarkers (8). So, in order to improve and appraise strategies for the prevention and treatment of AKI, there is a great need for further evaluation for estimation of accurate cut-off point for NGAL in kidney transplant recipients. Comparing with previous studies (13-15) which considered plasma NGAL as an early and sensitive biomarker of the AKI commencement, it is appropriate to assess urinary NGAL in renal transplant recipients as a special model. On the other hand, several studies with different age, gender and race should be performed for decisionmaking cut-off.

\section{Objectives}

In this study, we conducted a prospective study to examine the results of the few earlier studies that evaluated diagnostic value of urinary NGAL in the prediction of early graft dysfunction in kidney transplant recipients among Iranian population. As urinary NGAL has been suggested to represent kidney damage better than plasma NGAL, we chose urine as sample material (16). We aimed to obtain a cut off point for NGAL until identify early graft dysfunction in a healthy kidney which transplanted to the other individual (17).

\section{Patients and Methods}

\subsection{Participants}

In a prospective cohort study, 64 adult patients aged more than 18 years old were consecutively included. They underwent kidney transplantation for the first time at Baqiyatallah transplant center between April 2009 and January 2010 . The majority of patients (86\%) received a kidney from a living donor. Patients who had history of recent (within one month ago) infectious diseases or inflammatory disorders were excluded from the operation and subsequently from the study. Patients divided into two groups based on the presence or absence of early graft dysfunction. The proposal of this study was approved by the local ethics committee of Baqiyatallah university of medical sciences and written informed consent was given from all patients.

\subsection{Immunosuppressive Regimen}

All patients received triple immunosuppressive therapy: (1) Cyclosporine (targeting a trough level of 200 to $300 \mathrm{ng} / \mathrm{mL}$ for first 3 months, 100 to $250 \mathrm{ng} / \mathrm{mL}$ for 4 to 12 months and 100 to $150 \mathrm{ng} / \mathrm{mL}$ thereafter); (2) Mycophenolate mofetil (1-2 g per day) or Azathioprine (1-2 mg/kg per day) and (3) Prednisolone (initially $1 \mathrm{mg} / \mathrm{kg}$ daily with tapering to 5-10 mg per day during 3 to 6 months). Antithymocyte globulin (ATG) was routinely administered in highly sensitized patients.

\subsection{Clinical Parameters of Allograft Function}

Early kidney allograft function was monitored by daily measurement of serum Cr, urinary out-put (amount of diuresis), and estimated GFR (eGFR) levels within the first 10 days after transplantation. The eGFR values were calculated according to the modification of diet in renal diseases $\left(\right.$ MDRD) formula $\left(\mathrm{eGFR}=186 \times(\text { serum } \mathrm{Cr})^{-1.154} \times\right.$ $(\text { age })^{-0.203} \times[0.742$ if female $] \times[1.210$ if black $\left.]\right)$. We considered an excellent renal allograft function if a serum $\mathrm{Cr}$ level less than $1.5 \mathrm{mg} / \mathrm{dL}$ on the second postoperative day. According to previous studies $(6,16,18,19)$, kidney function after transplantation divided into three groups including immediate graft function (IGF), slow graft function (SGF), and delayed (DGF) graft function. Acute renal failure due to DGF defined as the need for dialysis within the first week after transplantation (1), while AKI due to SGA defined as recipients who do not have a rapidly falling serum $\mathrm{Cr}$ level after transplantation, but do have sufficient kidney function to avoid the need for dialysis (19). Therefore in this study, early graft dysfunction or post transplantation AKI was defined as Cr level more than 1.5 $\mathrm{mg} / \mathrm{dL}$ on the second postoperative day.

\subsection{Clinical and Biochemical Data Collection}

Data collected from all patients included age and gender of recipient and donors, donor source (living and deceased), renal function, cold and warm ischemic times, Cyclosporine level, underling disease, blood pressure, urinary out-put, sodium, potassium, calcium, magnesium, AST (aspartate aminotransferase), ALT (alanine aminotransferase), and hemoglobin.

\subsection{The Urinary NGAL Measurement}

We measured the urinary NGAL level in only 10 patients before transplantation, while urine sample could not be obtained in 54 cases because of oligo-anuria. The urinary samples for determination of NGAL levels were taken at 2, 6, 12, 24 and 48 hours after surgery. Almost $5 \mathrm{~mL}$ urine 
sample was collected and immediately centrifuged at $3000 \mathrm{rpm}, 4{ }^{\circ} \mathrm{C}$, for 5 minutes, and the supernatant was stored at $-70{ }^{\circ} \mathrm{C}$. In the current study, urinary NGAL was measured by means of a commercially available ELAISA test kit (Antibody Shop, Gentofte, Denmark).

\subsection{Statistical Analysis}

Statistical analyses were performed using the SPSS version 17.0 for Windows. All quantitative data have been expressed as mean \pm SD and the qualitative variables have been shown by percentage. Repeated measurement and ANOVA was used to evaluate the differences of markers between two groups. Independent variables with a P value $\leq 0.2$ in the univariate analysis were entered into the multivariate linear regression model.

To measure the sensitivity and specificity of urinary NGAL at different cut-off values, a conventional receiver operating characteristic (ROC) curve was generated at 2 ,
6, 12, 24 and 48 hours after kidney transplantation. We calculated the area under the curve (AUC) to ascertain the quality of urinary NGAL as an early graft dysfunction diagnostic biomarker. An area of 0.5 is no better than expected by chance, whereas a value of 1.0 signifies a perfect biomarker. The optimal cutoff level was defined by the largest sum of sensitivity and specificity. P value less than 0.05 was statistically considered significant.

\section{Results}

\subsection{Demographic and Laboratory Characteristics of Recipients}

We enrolled 64 kidney transplant recipients. The most common known causes of end stage renal disease were hypertension (37.5\%) and diabetes mellitus (10.9\%). Table 1 demonstrates demographic and laboratory characteristics.

Table 1. Demographic and Laboratory Characteristics of Recipients

\begin{tabular}{|c|c|}
\hline Charactristics & \\
\hline Gender & \\
\hline Male & $46(71.9)$ \\
\hline Female & $18(28.1)$ \\
\hline Primary disease number (\%) & \\
\hline $\mathrm{ADPKD}^{\mathrm{a}}$ & $3(4.7)$ \\
\hline Diabetes mellitus & $7(10.9)$ \\
\hline Hypertension & $24(37.5)$ \\
\hline Renal stone & $1(1.6)$ \\
\hline Unknown & $29(45.3)$ \\
\hline Urinary out-put (mL/24 h) & $4300 \pm 1406$ \\
\hline Age, $y$ & $40.4 \pm 14.1$ \\
\hline Serum creatinine $(\mathrm{mg} / \mathrm{dL})$ & \\
\hline Pre-transplantation & $8.5 \pm 2.5$ \\
\hline 2 weeks after transplantation & $2.1 \pm 0.9$ \\
\hline Hemoglobin $(\mathrm{g} / \mathrm{dL})$ & \\
\hline Pre-transplantation & $11.2 \pm 1.7$ \\
\hline 2 weeks after transplantation & $10.6 \pm 1.8$ \\
\hline Dialysis vintage, mo & $20.1 \pm 19.8$ \\
\hline Cold ischemic time, min & $17.3 \pm 1.4$ \\
\hline Warm ischemic time, min & $16.8 \pm 1.1$ \\
\hline Cyclosporine dose (mg/d) & $368 \pm 58$ \\
\hline Magnesium (mg/dL) & $2.14 \pm 0.58$ \\
\hline Cyclosporine through level (ng/mL) & $271 \pm 143$ \\
\hline Cyclosporine 2 hour post dose (ng/mL) & $505 \pm 288$ \\
\hline Uric acid (mg/dL) & $5.06 \pm 1.39$ \\
\hline Aspartate aminotransferase (AST) (units/L) & $34 \pm 51$ \\
\hline Alanine aminotransferase (ALT) (units/L) & $37 \pm 31$ \\
\hline Phosphorus (mg/dL) & $3.0 \pm 0.9$ \\
\hline
\end{tabular}


Calcium (mg/dL)

Fasting blood sugar $(\mathrm{mg} / \mathrm{dL})$

Potassium ( $\mathrm{mmol} / \mathrm{L})$

Sodium $(\mathrm{mmol} / \mathrm{L})$

${ }^{a}$ Abbreviation: ADPKD, autosomal dominant polycystic kidney disease
$8.48 \pm 0.54$

$117 \pm 45$

$4.2 \pm 0.3$

$136.5 \pm 3.5$

\subsection{Demographic and Laboratory Characteristics of Donors}

The mean age of donors was $28.6 \pm 6$ years with the mean hemoglobin level of $15.4 \pm 1.1 \mathrm{~g} / \mathrm{dL}$ and mean serum Cr concentration of $0.9 \pm 0.1 \mathrm{mg} / \mathrm{dL}$. A total of 55 patients received a kidney from a living donor, while 9 transplants were carried out using a kidney from a deceased donor. Male to female ratio was 3.9:1 (79.7\% vs. 20.3\%).

\subsection{AKI Group Versus Non- AKI Group}

More than $50 \%$ of our patients had excellent renal allograft function. Post-transplant AKI was observed in 31 recipients including 18 patients who had induction therapy with ATG, 4 cases with DGF. Twenty-four subjects had serum $\mathrm{Cr}$ level of more than $1.5 \mathrm{mg} / \mathrm{dL}$ after $48 \mathrm{~h}$ of transplantation. The patients with AKI had higher donor age $(P=0.03)$, greater post-operative serum phosphorus

\begin{tabular}{|c|c|c|c|}
\hline & Without AKI Number (\%) & With AKI Number (\%) & Pvalue \\
\hline Recipient gender & & & 0.1 \\
\hline Female & $12(66.6)$ & $6(33.3)$ & \\
\hline Male & $21(45.7)$ & $25(54.3)$ & \\
\hline Donor gender & & & 0.4 \\
\hline Female & $2(50)$ & $2(50)$ & \\
\hline Male & $28(54.9)$ & $23(45.1)$ & \\
\hline Hypertensive recipient & & & 0.4 \\
\hline No & $17(47.2)$ & $19(52.8)$ & \\
\hline Yes & $16(57.1)$ & $12(42.9)$ & \\
\hline Diabetic recipient & & & 0.6 \\
\hline No & $29(50.9)$ & $28(49.1)$ & \\
\hline Yes & $3(50)$ & $3(50)$ & \\
\hline Blood transfusion & & & 0.5 \\
\hline No & $31(52.5)$ & $28(47.5)$ & \\
\hline Yes & $2(40)$ & $3(60)$ & \\
\hline $\begin{array}{l}\text { Furosemide + manitol infu- } \\
\text { sion during operation }\end{array}$ & & & 0.8 \\
\hline No & $19(54.3)$ & $16(45.7)$ & \\
\hline Yes & $14(48.3)$ & $15(51.7)$ & \\
\hline Donor type & & & 0.2 \\
\hline Deceased & $3(33.3)$ & $6(66.6)$ & \\
\hline Living & $30(54.5)$ & $25(45.5)$ & \\
\hline Donor hemoglobin $(\mathrm{g} / \mathrm{dL})$ & $15.5 \pm 1.2$ & $15.4 \pm 1.1$ & 0.6 \\
\hline Donor creatinine (mg/dL) & $0.92 \pm 0.15$ & $0.95 \pm 0.14$ & 0.4 \\
\hline $\begin{array}{l}\text { Donor fasting blood sugar } \\
\text { (mg/dL) }\end{array}$ & $89 \pm 7$ & $92 \pm 10$ & 0.3 \\
\hline Donor urine out-put (mL/d) & $1544 \pm 603$ & $1702 \pm 743$ & 0.4 \\
\hline Donor age, y & $27.0 \pm 4.5$ & $30.5 \pm 7.1$ & 0.03 \\
\hline
\end{tabular}




\begin{tabular}{|c|c|c|c|}
\hline $\begin{array}{l}\text { Recipient hemoglobin pre- } \\
\text { operation }(g / d L)\end{array}$ & $11.4 \pm 1.5$ & $11.0 \pm 1.9$ & 0.4 \\
\hline $\begin{array}{l}\text { Recipient creatinine pre- } \\
\text { operation }(\mathrm{mg} / \mathrm{dL})\end{array}$ & $8.18 \pm 2.87$ & $8.87 \pm 2.12$ & 0.2 \\
\hline $\begin{array}{l}\text { Recipient urine out-put } \\
(\mathrm{mL} / \mathrm{d})\end{array}$ & $422 \pm 390$ & $393 \pm 357$ & 0.7 \\
\hline Recipient age, $y$ & $41.7 \pm 15.3$ & $39.1 \pm 12.9$ & 0.4 \\
\hline Dialysis vintage, mo & $19.1 \pm 20.6$ & $21.2 \pm 19.4$ & 0.7 \\
\hline Cold ischemic time, min & $17.4 \pm 1.2$ & $17.2 \pm 1.6$ & 0.6 \\
\hline Warm ischemic time, min & $16.8 \pm 1.0$ & $16.8 \pm 1.2$ & 0.9 \\
\hline Sandimon dose (mg/d) & $358 \pm 63$ & $379 \pm 51$ & 0.1 \\
\hline Magnesium (mg/dL) & $2.3 \pm 0.7$ & $2.0 \pm 0.4$ & 0.1 \\
\hline $\begin{array}{l}\text { Cyclosporine } 2 \text { hour post } \\
\text { dose }(\mathrm{ng} / \mathrm{mL})\end{array}$ & $554 \pm 233$ & $444 \pm 373$ & 0.6 \\
\hline $\begin{array}{l}\text { Cyclosporine through level } \\
\text { (ng/mL) }\end{array}$ & $306 \pm 141$ & $236 \pm 139$ & 0.08 \\
\hline Uric acid (mg/dL) & $4.9 \pm 1.5$ & $5.3 \pm 1.2$ & 0.3 \\
\hline $\begin{array}{l}\text { Aspartate aminotransferase } \\
\text { (AST) (units/L) }\end{array}$ & $39 \pm 70$ & $29 \pm 18$ & 0.4 \\
\hline $\begin{array}{l}\text { Alanine aminotransferase } \\
\text { (ALT) (units/L) }\end{array}$ & $33 \pm 22$ & $40 \pm 38$ & 0.3 \\
\hline Phosphorus (mg/dL) & $2.7 \pm 0.7$ & $3.2 \pm 1.1$ & 0.03 \\
\hline Calcium (mg/dL) & $8.6 \pm 0.5$ & $8.3 \pm 0.5$ & 0.03 \\
\hline Fasting blood sugar $(\mathrm{mg} / \mathrm{dL})$ & $114 \pm 45$ & $120 \pm 45$ & 0.5 \\
\hline Potassium (mmol/L) & $4.2 \pm 0.3$ & $4.2 \pm 0.3$ & 0.8 \\
\hline Sodium (mmol/L) & $137.1 \pm 3.7$ & $135.9 \pm 3.3$ & 0.2 \\
\hline Creatinine $(\mathrm{mg} / \mathrm{dL})$ & $1.57 \pm 0.44$ & $2.64 \pm 1.06$ & 0.000 \\
\hline $\begin{array}{l}\text { Hemoglobin post-operation } \\
\text { (g/dL) }\end{array}$ & $11.1 \pm 1.7$ & $10.1 \pm 1.8$ & 0.02 \\
\hline $\begin{array}{l}\text { Systolic blood pressure } \\
(\mathrm{mmHg})\end{array}$ & $132 \pm 12$ & $138 \pm 12$ & 0.1 \\
\hline $\begin{array}{l}\text { Diastolic blood pressure } \\
\text { (mmHg) }\end{array}$ & $79 \pm 4$ & $110 \pm 157$ & 0.2 \\
\hline Urine out-put (mL/d) & $4277 \pm 1289$ & $4323 \pm 1541$ & 0.8 \\
\hline $\operatorname{GFR}(\mathrm{mL} / \mathrm{min})$ & $55.9 \pm 16.2$ & $38.3 \pm 17.6$ & 0.01 \\
\hline
\end{tabular}

value $(P=0.03)$ and lower serum calcium $(P=0.03)$ and hemoglobin levels $(\mathrm{P}=0.02)$ compared to no-AKI individuals (Table 2). There were no statistically significant differences in other variables between two groups (Table 2).

The mean urinary NGAL level was greater in recipients with AKI as compared to patients who had no AKI $(P=0.024)$ (Figure 1). In linear regression model, AKI was the only factor affected on urinary NGAL level ( $\mathrm{B}=$ 299.8, P=0.009).

The best sensitivity and specificity for AKI detection by serum Cr observed at seven ${ }^{\text {th }}$ day Table 3, while by urinary NGAL observed at 2 hour after operation with cut-off point $204 \mathrm{ng} / \mathrm{mL}$ (Table 4).

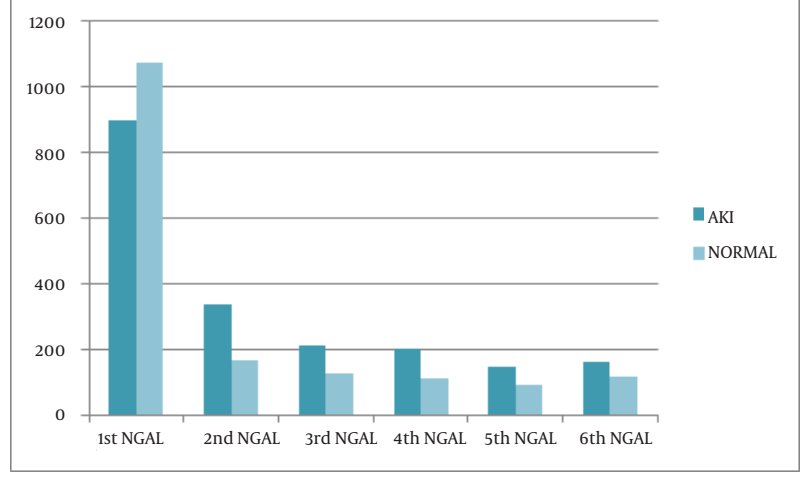

Figure 1. Urinary NGALComparison Between 2 Groups 


\begin{tabular}{llll}
\hline \multicolumn{2}{l}{ Table 3. Sensitivity and Specificity for AKI During Different Day After Kidney Transplantation } & \\
\hline & Cut Off Point & Sensitivity \% & Specificity \% \\
\hline Cr 1th day & 1.55 & 81 & 37 \\
\hline Cr 2th day & 1.55 & 68 & 81 \\
\hline Cr 3th day & 1.55 & 68 & 81 \\
\hline Cr 4th day & 1.60 & 68 & 78 \\
\hline Cr 5th day & 1.55 & 75 & 81 \\
\hline Cr 6th day & 1.55 & 81 & 84 \\
\hline Cr 7th day & 1.55 & 87 & 87 \\
\hline Cr 8th day & 1.55 & 81 & 75 \\
\hline
\end{tabular}

Table 4. Sensitivity, Specificity and Cut off Point for Urinary NGAL Level During Different Hour Post Operation, for AKI Detection

\begin{tabular}{llllllll}
\hline & Cut off Point & Sensitivity, \% & Specificity, \% & AUC & $\begin{array}{l}\text { Confidence } \\
\text { Interval }\end{array}$ & Pvalue \\
\hline NGAL $^{\text {a } 2 t h ~ h ~}$ & 204 & 72 & 67 & 0.713 & $0.563-0.863$ & 0.009 \\
\hline NGAL 6th h & 80 & 61 & 40 & 0.612 & $0.447-0.778$ & 0.08 & 0.07 \\
\hline NGAL 12th h & 68 & 83 & 43 & 0.630 & $0.480-0.780$ & 0.02 \\
\hline NGAL 24th h & 77 & 72 & 64 & 0.681 & $0.542-0.820$ & 0.02 \\
\hline NGAL 48th h & 77 & 72 & 63 & 0.638 & $0.490-0.785$ & 0.09 & \\
\hline
\end{tabular}

a Abbreviation: NGAL, neutrophil gelatinase associated lipocalin

Table 3 lists the derived sensitivities, specificities, and predictive values at different cut-off concentrations. The area under the curve (AUC) for 2 hour post-operation urinary NGAL was 0.71 (confidence interval 95\% (CI95\%): $0.563-0.863 ; \mathrm{P}=0.009$ ). At the optimal cutoff level of 204 $\mathrm{ng} / \mathrm{mL}$, the sensitivity was $72 \%$ and the specificity was $67 \%$. AUC-ROC analysis and cutoff level for the best sensitivity and specificity in different hours after transplantation are shown in Table 3.

\section{Discussion}

According to our study, measurement of urinary NGAL was a better predictor for AKI after kidney transplantation than serum creatinine. It is important to note that serum creatinine is not a reliable marker of AKI in kidney transplant patients (1). Therefore, the lack of early biomarkers for graft dysfunction after transplantation may lead to an unacceptable delay in initiating well-timed treatment (1). On the other hand, urine NGAL is significantly higher in patients who develop AKI compared to individuals who do not experience AKI in the early period after transplantation $(3,20)$. Although a number of studies in which patients experienced AKI have demonstrated the use of both urine and plasma NGAL are powerful independent predictors of AKI with a different proposed cut-offs for optimum utility of this test ranging from 10 to $550 \mathrm{ng} / \mathrm{mL}(4,7,9,21)$, there is no clear guidance to offer the using of NGAL in AKI. This wide range could be due to contributing variables such as age, sex, race and preexisting kidney disease which can cause difference to baseline measurement (7).

Our study showed in those who subsequently developed AKI the best AUC-ROC observed at a cut-off value of $204 \mathrm{ng} / \mathrm{mL}$ after 2 hour post transplantation, this is in agreement with results obtained by Devarjan et al. (8) and Haase et al. (21) who revealed urine NGAL within 2-6 h after cardiac surgery may predict AKI with a AUCROC more than 0.9 and 0.78 respectively. In addition, we found that a cut-off value of $204 \mathrm{ng} / \mathrm{mL}$ for urine NGAL at $2 \mathrm{~h}$ after operation had the best sensitivity and specificity, while the best sensitivity and specificity for serum $\mathrm{Cr}$ level can be observed at least 5-7 day delay in AKI detection.

\subsection{The Best Timing for Urine NGAL Measurement}

In terms of diagnostic accuracy, Dent et al. (22) demonstrated that the best AUC, sensitivity and specificity of plasma NGAL measurement for prediction of AKI (0.96, 0.84 and 0.94 , respectively) were achieved at $2 \mathrm{~h}$ after cardiac surgery in a cut-off value of $150 \mathrm{ng} / \mathrm{mL}$. In children undergoing cardiac surgery, the severity of AKI was also correlated with the increase in urine NGAL levels detected at various time points after cardiopulmonary bypass. The urine NGAL at $2 \mathrm{~h}$ post-operation had an AUC of 0.95, sensitivity of 0.79 , and specificity of 0.92 for prediction of AKI using a cut-off value of $150 \mathrm{mg} / \mathrm{mL}(8,23)$. These find- 
ings have been confirmed in prospective studies of adults who experienced AKI following cardiac surgery, in whom urinary NGAL was considerably increased by 1 to 3 hours after the operation $(17,21)$. In a prospective multicenter study of adults and children undergoing kidney transplantation, urine and plasma NGAL levels in samples collected on the day of transplantation identified those who subsequently developed delayed graft function (which typically occurred 2 to 4 days later), with an AUC of 0.9 for urine NGAL (17). In the intensive care setting, urine and plasma NGAL measurements predict AKI about 2 days prior to the rise in serum $\mathrm{Cr}$, with high sensitivity and an AUC of 0.68 to $0.78(17,24)$. Furthermore, Cullen et al. (7) and Bennett et al. (23) reported patients who subsequently experienced AKI revealed significantly higher urinary NGAL levels immediately during third hour after surgery (Figure 2).

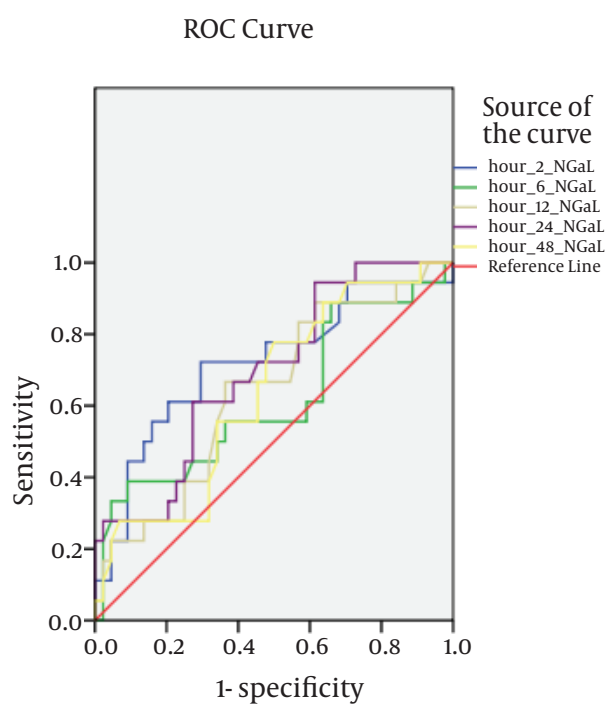

Diagonal segments are produced by ties.

Figure 2. Sensitivity and Specificity of NGAL Based on the Time of Urinary NGAL Measurement

These findings emphasize that the first hour after transplantation could be unique time for AKI revealing by urine NGAL measurement. Thus, NGAL is as an emerging tool could predict development of AKI even in various groups of recipients with multiple comorbid conditions and with unknown timing of initial kidney injury.

\subsection{NGAL Fluctuation During Early Period of AKI}

According to Figure 1, in excellent allograft function, urinary NGAL value was shown to decrease quickly during first 24 hour post-transplant period and after that slightly incrimination occurred during second day of transplantation. The urinary NGAL levels have previously been shown to be elevated in patients with chronic kidney disease (16). After successful transplantation, however, urinary NGAL must be decreased (25). In the immediate postoperative period, urine output may be important inducing NGAL dilution (13). On the other hand, a kidney transplant recipient in the first hour after operation often has a significant urine output, following aggressive fluid resuscitation, and thus baseline post-transplant NGAL results may be underestimated as a result of urinary dilution (7). So it can explain why urinary NGAL increased in $48^{\text {th }}$ hour.

Furthermore, in contrast to previous studies showed NGAL concentrations vary with age and gender (7), in our study no correlation was detected between urinary NGAL and age and gender.

Limitation: In fact, urinary NGAL might be very dilute early post-transplantation due to high urine out-put (13). Resulting to the synthesis and secretion of NGAL by damaged distal tubule cells, it seems the major fraction of urinary NGAL comes from this segment (8), also damaged tubular epithelium cannot reabsorb urine NGAL, filtered NGAL (8). Subsequently, the high urinary NGAL levels after kidney transplantation might just result from decreased GFR, but also might reflect ongoing damage in the kidney (25) and low urinary NGAL levels in oliguric patients after kidney transplantation suggest that oliguria might also be caused by other reasons, such as suboptimal fluid balance while kidney is in healthy condition (16).

In this study, we concluded urine NGAL at $2 \mathrm{~h}$ post-operation had the best sensitivity and specificity for prediction of AKI using a cut-off value of $204 \mathrm{ng} / \mathrm{mL}$. Taken together with the fact, it is clear that the role of NGAL in the diagnosis of post-operative AKI requires further investigation.

\section{Acknowledgements}

None declared.

\section{Authors' Contribution}

None declared.

\section{Financial Disclosure}

The authors declare no conflict of interest.

\section{Funding/Support}

This article was supported by the Nephrology and Urology Research Center of Baqiyatallah University of Medical Sciences.

\section{References}

1. Mishra J, Ma Q, Kelly C, Mitsnefes M, Mori K, Barasch J, et al. Kidney NGAL is a novel early marker of acute injury following transplantation. Pediatr Nephrol.2006;21(6):856-63.

2. Parikh CR, Jani A, Mishra J, Ma Q, Kelly C, Barasch J, et al Urine NGAL and IL-18 are predictive biomarkers for delayed graft function following kidney transplantation. Am J Transplant.2006;6(7):1639-45. 
3. Nguyen MT, Devarajan P. Biomarkers for the early detection of acute kidney injury. Pediatr Nephrol.2008;23(12):2151-7.

4. Feldkamp T, Bienholz A, Kribben A. Urinary neutrophil gelatinase-associated lipocalin (NGAL) for the detection of acute kidney injury after orthotopic liver transplantation. Nephrol Dialysis Transplant.2011;26(5):1456.

5. Rostami Z, Lessan-Pezeshki M. Role of NGAL for the Early Detection of Acute Kidney Injury. Nephro-Urol Mon.2010;2(3):387-389.

6. Hall IE, Yarlagadda SG, Coca SG, Wang Z, Doshi M, Devarajan P et al. IL-18 and urinary NGAL predict dialysis and graft recovery after kidney transplantation. J Am Soci Nephrol.2010;21(1):189-7.

7. Cullen MR, Murray PT, Fitzgibbon MC. Establishment of a reference interval for urinary neutrophil gelatinase-associated lipocalin. Annal Clin Biochem.2012;49(Pt 2):190-3.

8. Devarajan P. Review: Neutrophil gelatinase associated lipocalin: A troponin like biomarker for human acute kidney injury. Nephrology. 2010;15(4):419-28.

9. Prabhu A, Sujatha DI, Ninan B, Vijayalakshmi MA. Neutrophil gelatinase associated lipocalin as a biomarker for acute kidney injury in patients undergoing coronary artery bypass grafting with cardiopulmonary bypass. Annal Vasc Surg.2010;24(4):525-31

10. Coca SG, Yalavarthy R, Concato J, Parikh CR. Biomarkers for the diagnosis and risk stratification of acute kidney injury: a systematic review. Kidney Int.2007;73(9):1008-16.

11. Coca SG, Parikh CR. Urinary biomarkers for acute kidney injury: perspectives on translation. Clin I Am Soci Nephrol.2008;3(2):481-90.

12. Shapiro NI, Trzeciak S, Hollander JE, Birkhahn R, Otero R, Osborn TM, et al. The Diagnostic Accuracy of Plasma Neutrophil Gelatinase-Associated Lipocalin in the Prediction of Acute Kidney Injury in Emergency Department Patients With Suspected Sepsis. Annal Emerg Med.2010;56(1):52-9. e1.

13. Bataille A, Abbas S, Semoun O, Bourgeois É, Marie O, Bonnet F, et al. Plasma Neutrophil Gelatinase-Associated Lipocalin in Kidney Transplantation and Early Renal Function Prediction. Transplantation.2011;92(9):1024.

14. Kusaka M, Kuroyanagi Y, Mori T, Nagaoka K, Sasaki H, Maruyama $\mathrm{T}$, et al. Serum neutrophil gelatinase-associated lipocalin as a predictor of organ recovery from delayed graft function after kidney transplantation from donors after cardiac death. Cel
Transplant.2008;1(2):129-34.

15. Cruz DN, De Cal M, Garzotto F, Perazella MA, Lentini P, Corrad $\mathrm{V}$, et al. Plasma neutrophil gelatinase-associated lipocalin is an early biomarker for acute kidney injury in an adult ICU population. Intens Care Med.2010;36(3):444-51.

16. Hollmen ME, Kyllönen LE, Inkinen KA, Lalla MLT, Salmela KT. Urine neutrophil gelatinase-associated lipocalin is a marker of graft recovery after kidney transplantation. Kidney Int.2010;79(1):89-98.

17. Devarajan P. NGAL in acute kidney injury: from serendipity to utility. Am J kidney Dis.2008;52(3):395.

18. Johnston O, O'Kelly P, Spencer S, Donohoe J, Walshe JJ, Little DM, et al. Reduced graft function (with or without dialysis) vs immediate graft function-a comparison of long-term renal allograft survival. Nephrol Dialys Transplant.2006;21(8):2270.

19. Humar A, Ramcharan T, Kandaswamy R, Gillingham K, Payne WD, Matas AJ. Risk factors for slow graft function after kidney trans plants: a multivariate analysis. Clin Transplant.2002;16(6):425-9.

20. Koyner JL, Bennett MR, Worcester EM, Ma Q, Raman J, Jeevanandam V, et al. Urinary cystatin C as an early biomarker of acute kidney injury following adult cardiothoracic surgery. Kidney Int.2008;74(8):1059-69.

21. Haase M, Bellomo R, Devarajan P, Schlattmann P, Haase-Fielitz A Accuracy of neutrophil gelatinase-associated lipocalin (NGAL) in diagnosis and prognosis in acute kidney injury: a systematic review and meta-analysis. Am J kidney Dis.2009;54(6):1012-24

22. Dent C, Ma Q, Dastrala S, Bennett M, Mitsnefes M, Barasch J, et al. Plasma neutrophil gelatinase-associated lipocalin predicts acute kidney injury, morbidity and mortality after pediatric cardiac surgery: a prospective uncontrolled cohort study. Critical Care.2007;11(6):R127.

23. Bennett M, Dent CL, Ma Q, Dastrala S, Grenier F, Workman R, et al. Urine NGAL predicts severity of acute kidney injury after cardiac surgery: a prospective study. Clin J AM Soci Nephrol.2008;3(3):665.

24. Zappitelli M, Washburn KK, Arikan AA, Loftis L, Ma Q, Devarajan P, et al. Urine neutrophil gelatinase-associated lipocalin is an early marker of acute kidney injury in critically ill children: a prospective cohort study. Critical Care.2007;11(4):R84.

25. Mori K, Nakao K. Neutrophil gelatinase-associated lipocalin as the real-time indicator of active kidney damage. Kidney Int.2007;71(10):967-70. 